\title{
GEOGRAFIA DAS RELIGIÕES: TEMAS SOBRE A EXPERIÊNCIA E O PENSAMENTO NA ORDEM DOS FRADES MENORES CAPUCHINHOS
}

\author{
Geography of religious: Issues about experience \\ and thoughts of Capuchin Minor Friars Order
}

\author{
Elsbeth Lisa S. Becker* \\ Deise Caroline T. Lorensi**
}

\section{RESUMO}

Este artigo apresenta temas sobre a experiência e o pensamento na Ordem dos Frades Menores Capuchinhos, que evidenciam a riqueza da perspectiva cultural da Geografia, sua espacialização, sua presença social e espiritual

*Doutorado em Agronomia pela Universidade Federal de Santa Maria - UFSM/(2008). Mestrado em Engenharia Agrícola Área das Ciências Rurais pela Universidade Federal de Santa Maria - UFSM/(1999). Graduação em Geografia - Bacharelado pela Universidade Federal de Santa Maria - UFSM/(1996). Graduação em Geografia - Licenciatura Plena pela Universidade Federal de Santa Maria - UFSM/(1994). Atualmente é professora adjunta no Centro de Ciências Humanas do Centro Universitário Franciscano e professora da rede pública estadual atuando no Ensino Médio do Instituto São José de Santa Maria. Publicou o livro "História do pensamento geográfico" destinado aos alunos da graduação em Geografia. Membro da comissão editorial da Revista Disciplinarium Scientia, Série Humanas (UNIFRA). Membro da comissão avaliadora da Revista Ensino \& Pesquisa (UFSM) e da Revista Ciência \& Natura (UFSM). Orienta trabalhos de pesquisa e de extensão, com ênfase nos seguintes temas: geografia, turismo, ensino, antropologia, história natural e ambiental.

**Acadêmica do curso de Geografia no Centro Universitário Franciscano (UNIFRA), bolsista da Coordenação de Aperfeiçoamento de Pessoal de Nível Superior (CAPES), no Programa Institucional de Bolsa de Iniciação à Docência (PIBID), Subprojeto: Geografia/ UNIFRA. Foi representante discente da Área de Ciências Humanas no Conselho Universitário (Consun) da UNIFRA, no período de maio/2013 a maio/2014, nomeada pela portaria n 39/2013, de 20 de maio de 2013.

\begin{tabular}{|l|l|l|l|l|l|}
\hline Teocomunicação & Porto Alegre & v. 44 & n. 2 & p. 196-219 & maio-ago. 2014 \\
\hline
\end{tabular}


em diferentes fatos históricos. Visa-se a conhecer e a descrever a Ordem dos Frades Menores Capuchinhos, com ênfase à sua presença no estado do Rio Grande do Sul, Brasil, descrevendo atitudes, valores, entre outros aspectos, vinculados ao sentido e aos símbolos espiritualizados deste clero. Identificou-se o contexto da imigração italiana, no século XIX, e a consequente inserção dessa Ordem no Rio Grande do Sul como ponto de partida. A metodologia consistiu em uma análise documental, em textos de comentadores da filosofia franciscana e de entrevistas realizadas com oito frades Capuchinhos que pertencem à Província Sagrado Coração de Jesus. $\mathrm{O}$ artigo, pela complexidade do tema, não pode tratar detalhadamente da descrição da Ordem e dos símbolos em sua profundidade espiritual. Apenas destacou-se a abrangência geográfica dessa Ordem no Estado gaúcho e no Brasil e, também, nos países latino-americanos como Haiti e República Dominicana e evidenciou-se a vida religiosa consagrada, pela sua natureza, inserida na Igreja, contribuindo com sua presença e missão para o bem do povo de Deus. Constatou-se que o simbolismo franciscano está presente na atual sociedade, mesmo que esta não perceba, principalmente, difundido através do presépio e do Tau; e que os votos e a saudação de "Paz e Bem" apresentam maiores significados para aqueles que praticam essa filosofia de vida.

Palavras-chave: Província Sagrado Coração de Jesus. Espiritualidade. Cultura. Imigração italiana no Rio Grande do Sul.

\section{ABSTRACT}

This article presents issues about the experience and thought of Capuchin Minor Friars Order, which show the wealth of geography cultural perspective, its spatial, social and spiritual presence in different historical facts. The aim is to discover and describe the Capuchin Minor Friars Order, emphasizing its presence in Rio Grande do Sul state, Brazil, showing attitudes, values, among other thing, and relating the meaning and symbols of this spiritualized clergy. The starting point was the Italian immigration context in the nineteenth century, and the consequent entry of this Order in Rio Grande do Sul. The methodology consisted of a documental review, on texts by the Franciscan philosophy and interviews with eight Capuchin friars belonging to Heart Sacred of Jesus Province. The article can't treat with detail the description of the Order and symbols in their spiritual depth because the complexity of subject. The aim is highlight the geographic scope of this Order in gaucho state and Brazil, and also in Latin American countries, Dominican Republic and Haiti, and show the consecrated religious life, by nature inserted in Church, contributing with presence and mission for the good of God's people.

Keywords: Sacred Heart Province. Spirituality. Culture. Italian Immigration in Rio Grande do Sul. 


\section{Introdução}

A vida humana é repleta de símbolos que assumem significados, instituem valores e constroem uma identidade que caracteriza grupos de pessoas, ao longo do tempo, e suas manifestações se espacializam na paisagem. A cultura engloba todas as formas de expressão do homem: o sentir, o agir, o pensar, o fazer, bem como as relações entre os seres humanos e destes com o meio ambiente. A definição de cultura, nessa perspectiva abrangente, permite afirmar que o Brasil possui um patrimônio cultural diversificado e plural. Esses aspectos, da pluralidade e da diversidade cultural foram introduzidos a partir das diferentes correntes migratórias e de sua convivência no espaço geográfico brasileiro. No Estado do Rio Grande do Sul, a pluralidade cultural efetivada pelas diferentes correntes migratórias introduziu territorialidades representadas pela ocupação da terra, relação com o meio ambiente, arquitetura, culinária, folclore, língua e religiosidade.

A Geografia busca evidenciar as relações homem-natureza e, através da Geografia Cultural, visa a explicar a organização e reorganização do espaço geográfico. Desse modo, a cultura tornou-se uma importante indagação para essa ciência, uma vez que está expressa na paisagem e nas relações sociais de grupos de indivíduos que se identificam através dos códigos culturais.

Esses códigos culturais constituem a simbologia responsável pela visualização e, também, pela sua transmissão e, segundo Brum Neto (2007, p. 38), "encontram-se impressos nas diferentes paisagens, através do estilo das casas, vestuário típico, arte, gastronomia, música, religiosidade e festividades". Além desses, existem outros códigos que, embora não sejam visíveis, também são responsáveis pela materialização da cultura no espaço, como os valores religiosos, ideologias e convenções (BRUM NETO, 2007, p. 38).

Entre os códigos culturais, a religião é um dos mais expressivos e, segundo Claval (1999, p. 115), representam um elo social quase indissolúvel, uma vez que "partilhar as mesmas crenças religiosas ou metafísicas e participar dos mesmos ritos que reúnem os crentes constituem cimentos sociais muito sólidos".

Portanto, a religião assume uma dimensão fundamental na vida das pessoas, principalmente, entre os imigrantes, os quais tiveram nela um alicerce para lutar contra as dificuldades inerentes ao desconhecido. Brum Neto (2007, p. 45) destaca que "as migrações pressupõem perda 
de vínculo territorial e, também, um processo de adaptação frente à nova realidade a que se propõem. Ao sair do espaço vivido, o grupo social leva consigo a 'herança cultural', os hábitos, os valores e os costumes".

Diferentes correntes migratórias materializaram seus códigos culturais no espaço brasileiro e, dentre tantos, o cristianismo católico teve enorme expressividade, em diferentes períodos históricos, especialmente, representados pela etnia portuguesa e italiana, entre outras. Os símbolos religiosos como as igrejas, capitéis e grutas começam a ser construídos, seguindo o conhecimento de Portugal e, mais tarde, da Itália. Giron; Herédia (2007, p. 119) relatam que "a religião católica, por meio de suas igrejas, capelas e de seus ritos, estimulou um sentimento de unidade, constituindo o centro das comunidades".

Nessa perspectiva, pode-se considerar que, no Brasil, a criação de capitéis e de igrejas ocorre em épocas históricas distintas, mas por motivos semelhantes: "o aumento demográfico e a dificuldade dos paroquianos em realizar a peregrinação aos santuários existentes, distantes de suas paróquias" (CORRÊA; ROSENDAHL, 2001, p. 14).

A religião torna-se um importante código cultural, influenciando na vivência dos cristãos e convertendo novos adeptos. Tem-se a difusão de novas ideias, símbolos e a criação de lugares sagrados, que contribuíram para a manutenção de uma cultura que passou a registrar suas características, as marcas culturais, em suas colônias de imigração italiana, das quais o estado do Rio Grande do Sul teve expressiva representação nas colônias Conde D' Eu, Dona Isabel, Duque de Caxias e na Quarta Colônia de Imigração Italiana.

As colônias Conde D' Eu e Dona Isabel, na Serra Gaúcha, tiveram especial significado para o cristianismo católico, mas também representam um importante nicho de estudo para a Geografia das Religiões, uma vez que foram pioneiras, no sul do Brasil (no Rio Grande do Sul), ao territorializarem as primeiras expressões culturais, no continente americano, da Ordem dos Frades Menores Capuchinhos.

Assim, a questão de pesquisa que se estabelece é: "Quais são os valores e o simbolismo dessa ordem sacerdotal e como se organizam as inflexões sobre a sociedade contemporânea? E justifica-se sua contribuição para a Geografia da Religião, uma vez que "a religião só se mantém se sua territorialidade for preservada e, nesse sentido, podese acrescentar que é pela existência de uma religião que se cria um território e é pelo território que se fortalecem as experiências religiosas coletivas ou individuais" (CORRÊA; ROSENDAHL, 2003, p. 190). O 
espaço geográfico assume uma dimensão simbólica e cultural onde se fixam valores que definem uma identidade, nesse caso, o franciscanismo. Além disso, "é o bem simbólico que dá sentido e significado às práticas religiosas de diferentes grupos" (CORRÊA; ROSENDAHL, 2003, p. 190), tanto na interpretação individual, quanto na experiência coletiva (comunitária).

Em Aristóteles, ${ }^{1}$ a experiência integra-se dentro da estrutura antropológica do conhecimento e do pensamento e, por isso, não é fruto de uma percepção isolada, mas constitui uma percepção ou síntese de outras percepções unificadas e estruturadas por um fator comum que as unifica (MERINO, 1984).

Diante disso, o presente artigo apresenta temas sobre a experiência e o pensamento na Ordem dos Frades Menores Capuchinhos que evidenciam a riqueza da perspectiva cultural da Geografia, sua espacialização e sua influência espiritual na sociedade. Visa-se a conhecer e a descrever a Ordem dos Frades Menores Capuchinhos, com ênfase à sua presença no Estado do Rio Grande do Sul, Brasil, destacando atitudes, valores, símbolos, entre outros aspectos vinculados à identidade desse clero.

\section{Metodologia}

A metodologia consistiu em uma análise documental em textos de comentadores da filosofia franciscana. Descreveram-se aspectos da Ordem dos Frades Menores Capuchinhos e sua inserção em comunidades no Rio Grande do Sul e posterior espacialização no Brasil e na América Central. Foram realizadas entrevistas com oito frades Capuchinhos que pertencem à Província Sagrado Coração de Jesus, sendo três de votos perpétuos e cinco pós-noviciado (três gaúchos e dois haitianos), para compor a análise e destacar temas sobre a experiência e o pensamento na Ordem, sua espacialização e influência social.

\section{Pequena abordagem da Ordem dos Frades Menores Capuchinhos}

A Ordem dos Frades Menores Capuchinhos é uma ordem clerical, vinculada à Igreja Católica Apostólica Romana, que se originou no

Aristóteles: Metaphysica, A. 1, 981,b, 27. 
início do século XVI, na Itália. De acordo com Merlo (2005), Frei Mateus de Bascio (Ordem Franciscana Observante) percebeu que seu vestuário não correspondia com as que São Francisco de Assis usava. Diante disso, "passou a andar descalço, sozinho, vestindo um hábito curto, remendado, grosso e vil, com um capuz pontiagudo na cabeça" (MERLO, 2005, p. 251). Independente de sua vontade, ganhou adeptos como os irmãos Tenaglia (Frei Ludovico e Frei Rafael de Fossombrone).

Assim, os seus superiores tentaram conter essas inovações, porém, os três frades contaram com a acolhida dos padres Camaldulenses e o apoio de Catarina Cybo, duquesa de Camerino e sobrinha do Papa Clemente VIl. No dia 18 de maio de 1526, os frades receberam autorização do Papa para viverem de forma eremítica em áreas circunvizinhas de Camerino, na região dos Marche, na Itália.

Transcorria a primeira metade do século XVI e os tempos não eram de todo favoráveis à vida social, econômica e política. Havia tensões entre Igreja, senhores da terra e os comerciantes emergentes, e a situação socioeconômica apresentava problemas graves com o empobrecimento crescente da maioria da população. Nesse cenário, os Frades Menores de vida eremítica, como eram chamados inicialmente, "partilhavam tensões e orientações religiosas próprias do início do século XVI, que se manifestavam numa religiosidade interiorizada, alimentada pela oração secreta ou mental e centrada na contemplação de Cristo crucificado" (MERLO, 2005, p. 255). Os frades viveram na pobreza, na solidão contemplativa e foram presença solidária para as necessidades da sociedade, em geral, de extrema pobreza. As pregações eram feitas com simplicidade e entusiasmo, na linguagem popular, para a compreensão de todos, uma vez que a educação, deficiente, não era obrigatória e não se apresentava com perspectivas para os pobres que eram vistos como meros servos dos abastados.

É nesse contexto que se forma a Ordem dos Frades Menores Capuchinhos, considerados franciscanos reformistas, uma vez que se afastaram de suas ordens sacerdotais de origem e procuraram resgatar os ensinamentos de Francisco de Assis, e, assim, descobriram sua verdadeira identidade que se baseia "na unidade e na complementariedade dos seguintes binômios: evangelização e contemplação, evangelização e fraternidade, evangelização e pobreza" (CONTI, 2004, p. 11).

Para melhor compreensão dessa Ordem, entende-se que frade (irmão) é aquele que vive fraternalmente, repartindo os bens materiais, os dons, os saberes, entre outros; menor visto que respeita e acolhe 
todas as formas de vida, procurando manter a integridade da criação; capuchinho, nome dado devido ao capuz pontiagudo incorporado à túnica.

A prática experiencial dos Capuchinhos conduz à suave conciliação e à harmonia entre a razão simbólica e a razão dialética, que constituem a base da utopia franciscana. As vivências cotidianas dos Capuchinhos não se fundamentam em doutrinas filosóficas e teológicas, mas se orientam pela experiência religiosa, carismática e espiritual de Francisco de Assis, impregnada de fraternidade humana, cósmica, poética e amorosa. Ser Capuchinho é viver a experiência do movimento franciscano: "é um estilo de viver, um comportamento e um modo de tratar o mundo, os outros e a vida" (MERINO, 1982, p. 30).

\section{A inserção dos Capuchinhos nas comunidades de imigração italianas no Rio Grande do Sul}

A imigração italiana para o estado do Rio Grande do Sul iniciou em 1875, quando a primeira leva de imigrantes chegou ao Estado, proveniente de Piemonte, Tirol, Lombardia e Vêneto. Esse fato histórico é reforçado por Fausto (2000), ao alegar que, após 1870, o governo imperial de D. Pedro II incentivou a vinda de imigrantes, especialmente de italianos, para o Estado, e, entre 1882 e 1889, dos 41.616 imigrantes que ingressaram no Rio Grande do Sul, 34.418 eram italianos.

Em 1870, foram criadas pelo governo do da Província do Rio Grande do Sul colônias na região serrana, pois esperava-se a vinda de imigrantes alemães. Porém, as notícias de que os alemães estavam enfrentando problemas no território brasileiro fizeram, gradualmente, diminuir a vinda de imigrantes do Império Alemão e algumas dessas colônias não foram totalmente povoadas, entre elas Conde d'Eu e Dona Isabel, atuais municípios de Garibaldi e Bento Gonçalves, respectivamente (Figura 1). Assim, a colonização italiana foi uma estratégia geopolítica do Império do Brasil para povoar os vazios demográficos da região Sul.

O governo imperial de D. Pedro II preconizou alguns incentivos, que, divulgados na Europa, atraíram os imigrantes, especialmente, os italianos, cujo território ainda não apresentava uma unidade política de Estado e, a maioria da população ainda sobrevivia em meio à pobreza e à concentração de terras. Segundo Zagonel (1975), entre os atrativos divulgados pelo governo imperial brasileiro, destacavam-se: transporte gratuito, abrigo e assistência durante os primeiros anos, instrumentos de 


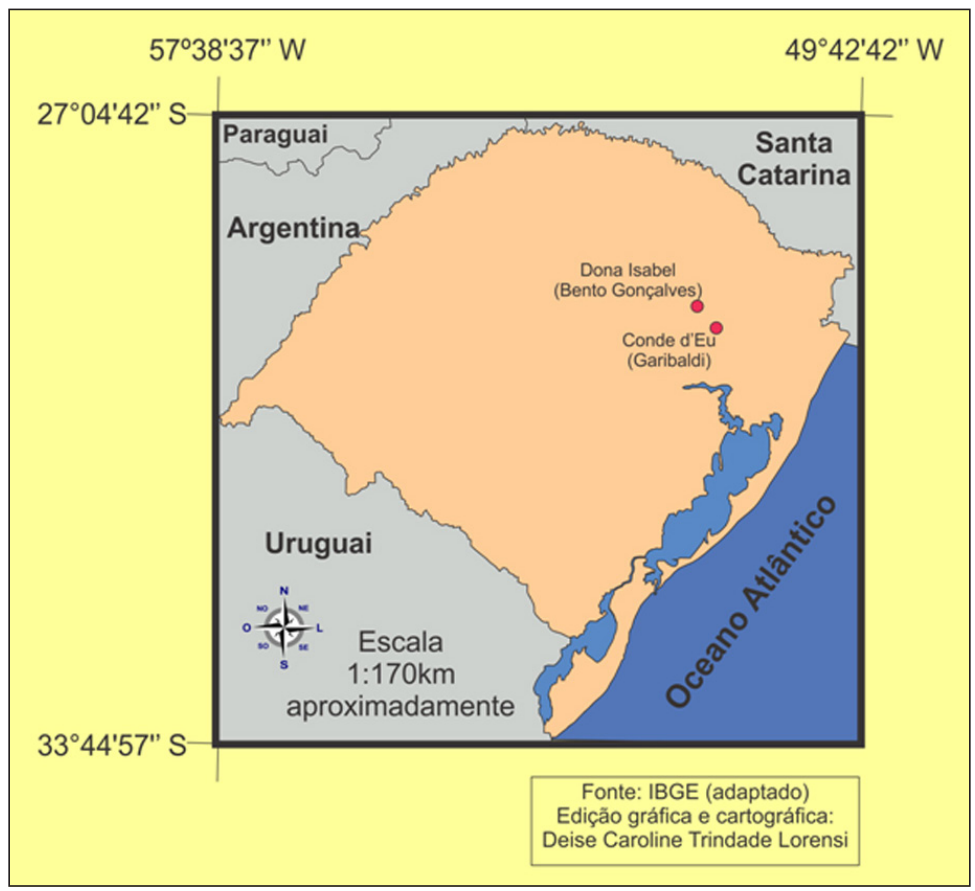

Figura 1 - Localização das colônias de Imigração Italiana de Conde d'Eu (atual Garibaldi) e Dona Isabel (atual Bento Gonçalves) no Rio Grande do Sul, local de destino dos primeiros missionários capuchinhos em território brasileiro. Fonte: <http://www.mapas.ibge.gov.br/> e adaptado por Lorensi, D. C. T.

trabalho, sementes, cuidados médicos, escolas e assistência religiosa. Porém, os imigrantes não foram assistidos em suas áreas de instalação pelo governo imperial e os colonos ficaram desamparados, tanto com a completa ausência de estrutura de transporte e de produção agrícola, como também, ficaram desassistidos na educação, saúde pública e vida social. Sobreviveram graças à solidariedade fraterna entre os integrantes das levas de imigrantes que iniciaram uma vida comunitária fortemente alicerçada na fé.

Com o intuito de promover uma assistência espiritual e pastoral aos imigrantes italianos, o bispo do Rio Grande do Sul, Dom Cláudio José Ponce de Leão, intercedeu junto ao Papa Leão XIII que encaminhasse missionários para o Estado. Assim, o Papa 
encaminhou o pedido ao Ministro Geral da Ordem dos Capuchinhos, Frei Bernardo de Andermatt, que, praticamente, obrigou a Província de Saboia a assumir o compromisso missionário independentemente do objetivo da procura de um 'refúgio temporário' (ZAGONEL, 2001, p. 354).

Porém, a proposta do pontífice encontrou resistência, uma vez que os missionários Capuchinhos, que eram franceses, procuravam um local para se estabelecerem, pois queriam salvar-se da perseguição contra todas as ordens sacerdotais movidas pela França, no final do século XIX, disseminadas na esteira do racionalismo e iluminismo nos círculos intelectuais. Os Capuchinhos também não queriam mais errar em suas decisões, como a experiência que tiveram na Ásia Ocidental. "A transferência dos estudantes para Ghazir, no Líbano, não foi um empreendimento missionário. Foi uma necessidade de sobrevivência e um estratagema para fugir do serviço militar" (ZAGONEL, 1996, p. 17). Porém, a fundação de Ghazir apresentou um custo econômico elevado e representou muita apreensão, devido às doenças contraídas que dizimavam os jovens frades e, em decorrência, a Ordem teve que arcar com altos custos econômicos e com baixas de vidas humanas.

A América, o Novo Mundo, era uma realidade intrigante e temerosa para os jovens frades que se viam diante de uma escolha difícil e a dúvida perseverava: Estados Unidos (América do Norte) ou Rio Grande do Sul, um local completamente desconhecido, na América do Sul. Após longos debates, reflexões, orações e extrema prudência na escolha, foi aprovada, no Definitório Provincial, a designação dos frades para o Rio Grande do Sul, assim descrita: "A missão do Rio Grande do Sul, em princípio, é aprovada e aceita, a fim de proceder com sabedoria, uma delegação, composta por dois ou três religiosos, irá tomar, inicialmente, conhecimento do lugar" (ZAGONEL, 2001, p. 354 apud APPRIEU, 1957).

Com a decisão de enviar os frades para o Estado, para avaliar o território sul-rio-grandense, foi necessário que os missionários escolhidos aprendessem o idioma local (português), bem como o italiano (dos imigrantes). Sendo assim, Frei Bruno de Gillonnay foi enviado a Portugal para estudar português, e Frei Leão de Montsapey foi para a Itália aperfeiçoar o italiano. De acordo com Zagonel, 
o provincial da Saboia, Frei Rafael de la Roche, acompanhado dos freis Bruno de Gillonnay e Leão de Montsapey, embarcaram em Bordeaux a 5-12-1895, chegando ao Rio de Janeiro a 22-12-1895, rumo a Montevidéu, para desembarcar no porto de Rio Grande a 2-1-1896 (1996, p. 19).

No dia 18 de janeiro de 1896, chegaram a Conde d'Eu (Garibaldi) os primeiros frades Capuchinhos no Rio Grande do Sul, lugar em que, até então, nenhum sacerdote tinha permanecido. Os colonos italianos, que não foram informados sobre o projeto episcopal, acompanharam surpresos e curiosos a chegada dos estranhos visitantes, "com hábito de São Francisco, longas barbas e chapéu de palha na cabeça" (Zagonel, 2001, p. 355).

Logo que chegaram, iniciaram seus trabalhos pastorais, pois o clero era insuficiente para tantos problemas sociais na época, devido ao descaso do governo imperial para com os colonos. Assim, a missão foi crescendo, bem como o número de religiosos, porém os compromissos aumentaram em ritmo acelerado. Aos poucos, vinham novos frades de Saboia, uma região do sudeste francês, fazendo-se necessário buscar novas habitações e, consecutivamente, os Capuchinhos foram expandindo-se no território gaúcho.

De acordo com Zagonel (2001), aos poucos foi necessário construir novas Casas de Formação, entre elas o Noviciado e a Filosofia, em Flores da Cunha (Nova Trento), no ano de 1899; o Seminário Menor, em Veranópolis (Alfredo Chaves), no ano de 1902; e, mais tarde, em 1935, foi construído o Convento para a Filosofia, na cidade de Marau, permanecendo a Teologia em Garibaldi até 1958, quando foi transferida para a capital do Estado, Porto Alegre. Além das Casas de Formação, os Capuchinhos promoveram a vinda das Irmãs de São José de Chambery e dos Irmãos Maristas para cuidar das escolas e da educação dos filhos dos colonos, bem como fundaram o jornal 'Staffetta Riograndense' (atual Correio Riograndense).

Os missionários Capuchinhos, de origem francesa, aos poucos foram retornando para sua terra, Saboia, devido à estabilidade das condições político-religiosas, na Europa, mas que, logo em seguida, enfrentaria um de seus piores cenários geopolíticos. Na primeira metade do século XX, a Europa seria o palco das duas grandes Guerras Mundiais. Dessa forma, a responsabilidade da missão capuchinha no 
Rio Grande do Sul, gradativamente, passava a ser administrada por frades brasileiros.

Frei Bruno retornou à França em 1924, deixando sua querida Missão, elevada à condição de Comissariado Provincial, já com quatro conventos (Garibaldi, Flores da Cunha, Veranópolis e Porto Alegre), duas residências (Vacaria e Sananduva), cinco paróquias (Flores da Cunha, Veranópolis, Vacaria, Sananduva e PaternonPorto Alegre), um jornal, 45 sacerdotes (12 franceses), 12 clérigos professos, 10 irmãos capuchinhos e 2 noviços (ZAGONEL, 2001, p. 359).

O espaço geográfico da atuação dos Capuchinhos se ampliou consideravelmente, abrangendo diferentes localidades e exercendo atividades na área da comunicação e da educação, além da assistência espiritual e de cultura geral. Com a partida de Frei Bruno, a "Missão Refúgio São Francisco" passou a ser administrada pelo Frei José de Bento Gonçalves, um dos primeiros Capuchinhos consagrado à vida religiosa no Rio Grande do Sul. Em 1939, a missão tornouse Custódia Provincial do Rio Grande do Sul e, em 1942, é proclamada Província Sagrado Coração de Jesus, do Rio Grande do Sul, pois, com a II Guerra Mundial, os Capuchinhos gaúchos tiveram dificuldades em comunicar-se com a Província de Saboia, necessitando, assim, tornarem-se independentes da província de origem.

É nessa realidade que se situa a utopia franciscana dos Capuchinhos que se inserem no lugar e para o lugar em que convivem como resposta à necessidade real das suas localidades e de seu povo.

\section{Os caminhos da Província Sagrado Coração de Jesus}

A Província Sagrado Coração de Jesus transferiu, em 1938, sua sede de Garibaldi para Caxias do Sul, onde os Capuchinhos também assumiram a direção do Seminário Diocesano de Caxias do Sul, no período de 1939 a 1949 (Zagonel, 2001).

Aos poucos, a presença dos Freis Capuchinhos no Rio Grande do Sul tornou-se numerosa, uma vez que passaram a ganhar novos adeptos (religiosos) que, em sua maioria, eram descendentes dos imigrantes europeus. Pode-se inferir que a originalidade do trabalho 
espiritual dos Capuchinhos da Província Sagrado Coração de Jesus certamente contribuiu para ampliar sua geografia e o número de seguidores, praticantes e simpatizantes. As dificuldades e as limitações com a falta de condições físicas e de apoio governamental ao processo educacional no Brasil e no Rio Grande do Sul não conseguiram tirar a liberdade de sonhar dos descendentes de imigrantes que viram nos Capuchinhos o seu esteio e amparo espiritual em meio aos improvisos que ainda estavam sujeitos na primeira metade do século XX.

Os Capuchinhos manifestaram, antes de tudo, amor pela vida e pelo semelhante e isso não ficou despercebido pelas comunidades. Sua grande capacidade de adaptarem-se às situações das comunidades e ajudar os habitantes a solucionar problemas cotidianos denotava solidariedade e indicava grandeza de sua personalidade de ser e viver para o bem comum. Por outro lado, os Capuchinhos da Província Sagrado Coração de Jesus certamente sabiam que não estavam expondo suas vidas inutilmente. O modo de viver e de fazer as coisas, as tarefas e os desafios eram vencidos, etapa por etapa, e esse caminho foi determinante para o processo de ampliação geográfica para além das fronteiras gaúchas.

Os freis da Província Sagrado Coração de Jesus estiveram presentes em São Paulo, Portugal, África, Nicarágua e França, ou seja, além das fronteiras gaúchas e também brasileiras, e colaboraram na consolidação da Província Nossa Senhora de Fátima - Brasil Central, na Região Centro-Oeste e Norte do Brasil, que abrange os estados de Goiás, de Mato Grosso do Sul e de Tocantins, bem como o Distrito Federal. Esta província representa um marco histórico e afetivo importante para a Ordem dos Frades Menores Capuchinhos, uma vez que foi a primeira circunscrição eclesiástica capuchinha a ter como tutela uma província brasileira, nesse caso, a Província Sagrado Coração de Jesus.

Atualmente, essa Província continua atenta ao trabalho eclesial e mantém a ênfase na custódia da vice-província São Francisco de Assis - Brasil Oeste, abrangendo as Regiões Centro-Oeste e Norte do Brasil, cujas sedes estão localizadas nos estados de Mato Grosso e Rondônia, bem como a custódia da vice-província Madre Dei Divino Pastor, na República Dominicana e Haiti, na América Central (Figura 2). 


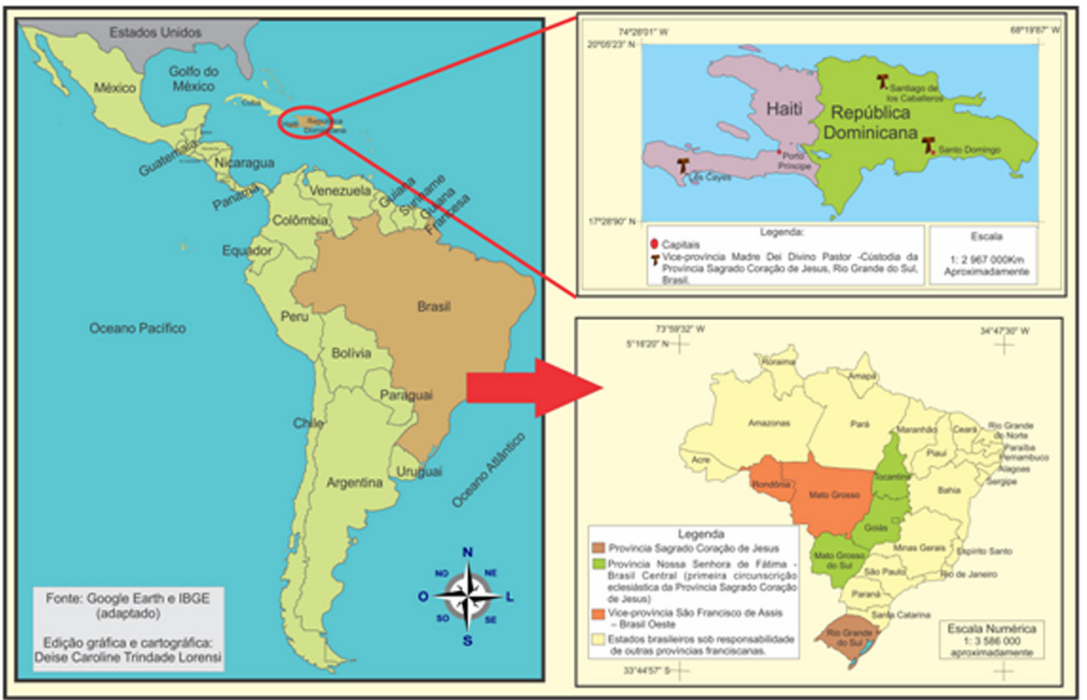

Figura 2 - Província Sagrado Coração de Jesus, Rio Grande do Sul, seus territórios de abrangência no Brasil, na América Central e a Província Nossa Senhora de Fátima - Brasil Central. Fonte: Google Earth e <http://www.mapas. ibge.gov.br $>$ e adaptado por LORENSI, D. C. T.

No Rio Grande do Sul, os Capuchinhos da Província Sagrado Coração de Jesus estão presentes nas cidades de Caxias do Sul (sede da Província), Bagé, Canoas, Flores da Cunha, Garibaldi, Ijuí, Ipê, Lagoa Vermelha, Marau, Pelotas, Porto Alegre, Rio Grande, Santa Maria, Soledade, Tramandaí, Vacaria, Veranópolis e Vila Flores, bem como se fazem presentes em Praia Grande e São João do Sul, sudeste de Santa Catarina (Figura 2).

A Província Sagrado Coração de Jesus, atualmente, está organizada em 28 fraternidades e com um número bem expressivo de freis que seguem essa filosofia de vida, constituído por um grupo de: 5 bispos, 220 frades de votos perpétuos, 27 frades pós-noviços, 13 noviços e 18 postulantes. Por sua vez, a Custódia compreende 5 fraternidades, com 36 frades de votos perpétuos, 12 pós-noviços, 6 noviços e 10 postulantes.

Nessa organização, a hierarquia faz parte da vivência dos Capuchinhos; no entanto, percebem e reconhecem que nenhum Irmão pode ser mais que o outro. Inspirados em Francisco, a experiência da 
fraternidade ultrapassa as relações impostas e exigidas pelas instituições e normas humanas e se alimenta na experiência de Deus. Diante disso, pode-se entender que as denominações são escolhas de vida e período dentro da Ordem e não se estabelecem subordinações. Assim, o aspirantado é a primeira etapa de vida formativa em que os jovens ingressam na fraternidade sem terem concluído o Ensino Médio; o pré-postulantado é o período de dez meses após o ano de iniciação, quando o jovem passará da orientação vocacional ou diretamente da família para pertencer à Província; o postulantado é a etapa na qual o jovem ingressa na fraternidade Capuchinha, continuando seu processo de formação por mais oito meses.

O noviciado constitui o período tido como o mais importante para a formação do jovem frade, pois, no término dessa etapa, este passará a usar o hábito franciscano e começará a ser chamado de frei, bem como é realizada a profissão temporária, ou seja, os primeiros votos de viver em pobreza, obediência e castidade, que são renovados a cada ano até o máximo de seis anos; e por último, o pós-noviciado que se caracteriza pelo aprofundamento e solidificação da vida religiosa franciscanocapuchinha, exercitando a vida fraterna e de oração e comunhão com Deus. Nessa fase, os freis cursam Filosofia e Teologia e preparamse para assumir definitivamente a vida religiosa, a partir dos Votos Perpétuos.

Além de serviços pastorais, das casas de formação e das paróquias, os freis Capuchinhos gerenciam a Editora São Miguel, o jornal 'Correio Riograndense', a Escola Superior de Teologia e Espiritualidade Franciscana (ESTEF), as redes de rádios Mais Nova FM e Rede Sul de Rádios e também administram cantinas e pousadas.

O mérito dos Capuchinhos da Província Sagrado Coração de Jesus é ter aberto perspectivas de escolhas e de vida, de espiritualidade e de evangelização, evidenciadas na vida religiosa, inseridas na Igreja, mas, especialmente, alicerçadas e reconhecidas na missão e na vivência da fraternidade para o bem do povo de Deus.

\section{Temas do pensamento franciscano e sua representação na prática experiencial dos Capuchinhos da Província Sagrado Coração de Jesus}

O universo simbólico "ordena a história e coloca todos os acontecimentos coletivos dentro de uma unidade coerente que inclui o 
passado, o presente e o futuro". ${ }^{2}$ Com relação ao passado, estabelece uma memória de que todos os indivíduos socializados dentro da coletividade compartilham, e o futuro estabelece um arco de referência comum para a projeção das ações individuais. E, assim, o universo simbólico vincula os homens com seus antepassados e sucessores em uma totalidade significativa, que serve para transcender a finitude da existência individual para um universo coletivo ao criar uma sensibilidade reconhecida pelo outro. Assim, o simbolismo franciscano implica que todo o homem se enraíza numa experiência fortemente vivida e compartilhada (MERINO, 1982), e se manifesta numa atitude fraternal, distinta e respeitosa para com todas as criaturas e, nesse dinamismo fraterno mais profundo e mais autêntico, concretizam-se a sensibilidade, a delicadeza, a cortesia, a ternura e a reverência. Na fraternidade universal e cósmica, acontece uma relação pessoal, alegre, livre e jovial.

A relação franciscana com o mundo das criaturas promove uma relação de integração fraterna, respeitosa e cordial com a natureza. A fraternidade com a natureza realiza-se no seguimento a Jesus Cristo, que se fez irmão de todas as criaturas pela encarnação e no amor a Deus, o criador de todas as criaturas. O simbolismo franciscano também leva em consideração alguns símbolos, representativos na espiritualidade e vinculados ao 'jeito de viver franciscano'. Levando em consideração o franciscanismo e a simbologia vinculada a essa filosofia de vida, procurou-se observar alguns símbolos que estão incorporados à Ordem dos Frades Menores Capuchinhos, a partir de depoimento dos freis franciscanos que residem em Santa Maria (RS), bem como sua influência na sociedade contemporânea. Assim, para compor o enfoque da análise deste artigo, elegeram-se alguns símbolos franciscanos, como a cruz de São Damião, o Tau, o Presépio, a saudação de 'Paz e Bem' e os votos perpétuos (de castidade, de pobreza e de obediência), que instituíram valores e construíram uma identidade, ao longo do tempo, e suas manifestações se espacializaram na paisagem.

A cruz de São Damião é um monumento histórico franciscano e universal, considerada um dos principais símbolos vinculados ao franciscanismo, uma vez que foi a partir deste símbolo que Francisco de Assis converteu-se e baniu-se de suas riquezas materiais para viver de maneira humilde em meio aos necessitados e conforme o Evangelho. Segundo Visalli (2013), Cristo teria se comunicado diretamente com

2 P. Berger e T. Luckmann: La construcción de la realidad (Amorrortu, B. A. 1976), p. 133. 
Francisco através do crucifixo, quando este teria entrado na igreja de São Damião para orar, constituindo-se um marco para a dedicação à vida religiosa. Considerando-se a ausência de registros mais explícitos, pode-se inferir que o crucifixo estava pendurado no centro da pequena capela, no abside, sobre o altar. Essa interpretação pode ser considerada, porque, naquele tempo, nas pequenas igrejas, a Eucaristia não era conservada, mas consumida em cada ceia.

Esse fato - o crucifixo 'fala' a Francisco - representa a admiração dedicada à Cruz de São Damião por pessoas do mundo inteiro e em diferentes épocas - leigos, estudiosos e devotos - e se traduz no simbolismo de uma extraordinária entrega ao Evangelho, iniciada pelo próprio Francisco ao ouvir que a imagem de Cristo Crucificado lhe fala: "Francisco, vai e reconstrói minha casa que está em ruína".

Francisco levou ao 'pé da letra' esse mandato e se incumbiu da reconstrução da igrejinha; mas a principal 'reconstrução' se daria no plano do simbolismo e da transcendência, ao realizar em si mesmo a mudança que queria para o mundo da época. Nas paragens conflitivas do período medieval, a 'reconstrução da casa' (a transformação da sociedade), "custou-lhe a abnegação de uma vida e exigiu-lhe o empenho de todas as energias que possuía” (MOREIRA, 2001, p. 72). Francisco empenhou-se na sua tarefa com alegria, no convívio fraterno e na evangelização.

De acordo com Visalli (2013), a cruz original de São Damião é de autoria anônima, provavelmente foi pintada no século XII, por um artesão da região da Úmbria, em tela tosca, colada sobre madeira de nogueira. A pintura é de estilo romântico, com influência oriental, siríaca e bizantina. A cruz "foi pintada em tela sobre madeira, de grande dimensão, mede pouco mais de dois metros de altura e um metro e trinta de largura, apresentando, além do Cristo, grande quantidade de personagens distribuídos de modo bastante equilibrado" (VISALLI, 2013, p. 90). Desde a morte de Francisco, foi levada para o convento das Pobres Damas e, somente na década de 1950, foi apresentada, em público, na Basílica de Santa Clara, em Assis, podendo ser visitada por devotos, turistas e estudiosos.

Pode-se perceber e, talvez, por isso inferir que a obra foi inspirada nos escritos do Evangelho do apóstolo João que relata, em várias passagens, a ressurreição de Cristo e a sua vitória sobre a morte. Ao observar-se a cruz de São Damião, percebe-se que Cristo não se 
encontra crucificado, mas repousa sobre o crucifixo, vivo, ressuscitado (Jo 12,32), de pé sobre o sepulcro vazio, representado pela cor preta. Cristo, com as mãos estendidas, está vivo para o mundo e pronto para subir ao céu (Jo 12,32).

O Tau também é um importante e significativo símbolo para os franciscanos e foi instituído pelo próprio Francisco. Na origem, o Tau é uma letra que aparece tanto no alfabeto hebraico quanto no grego, ou seja, "com alfabetos muito diferentes, têm, no entanto, uma letra com o mesmo nome e figura idêntica: é o T, em ambas as línguas chamado Tau" (VORREUX, s/d, p. 9).

$\mathrm{Na}$ Bíblia, existe apenas uma referência direta ao Tau, encontrada no livro do profeta Ezequiel $(9,4)$ : "Percorra a cidade e marca com um Tau na testa dos homens que gemem e choram por todas as práticas abomináveis que se cometem". Entretanto, nas Bíblias de traduções mais recentes, a palavra Tau foi traduzida como cruz ou sinal. Essa substituição de denominação, nas traduções mais recentes, provavelmente, decorre devido ao ' $\mathrm{T}$ ' (Tau) e a letra ' $\mathrm{T}$ ' terem a grafia em forma de cruz e ser considerada um sinal.

Francisco de Assis renovou e perpetuou o Tau, utilizando esse símbolo como selo pessoal.

São Francisco de Assis em suas cartas usava como assinatura o Tau. O Tau é a última letra do alfabeto hebraico e a décima nona do alfabeto grego, sendo a mais antiga em forma de Cruz (Depoimento Frei A). ${ }^{3}$

O Tau é a convergência das duas linhas: a verticalidade e a horizontalidade, e significam o encontro entre o Céu e a Terra, entre o Divino e o humano. Francisco, na busca pela conversão baseada no Evangelho de Jesus Cristo e na transformação pessoal (valorização da vida), utilizava o Tau como "rótulo sobre as portas e nas paredes das celas dos irmãos" (VORREUX, s/d, p. 16), uma vez que lembra a crucificação e o sangue do Cordeiro derramado para a salvação. A tradição franciscana ainda assinala que Clara de Assis, em sua profunda dedicação aos doentes, utilizava o Tau em suas orações pela cura e para o conforto espiritual dos desamparados. 3 Depoimento de um frei da Província Sagrado Coração de Jesus, concedido em 15 de
dezembro de 2013. 
Em 1215, Francisco de Assis, junto ao Papa Inocêncio III, assume o Tau como símbolo de sua Ordem religiosa: a Ordem dos Frades Menores e, assim, permanece até os dias atuais. O Tau, para os Capuchinhos, designa uma vida de conversão, de transformação e de missão em prol dos irmãos mais necessitados. Diante disso, este símbolo

identifica toda a comunidade franciscana, abarcando ao mesmo tempo uma ampla gama de valores culturais, advindo da tradição de São Francisco de Assis. Desse modo, uma das significâncias deste símbolo é a identificação e pertença ao grupo (Depoimento do Frei D). ${ }^{4}$

Logo, o Tau é um símbolo de profundo significado para os franciscanos, mas pouco reconhecido (identificado) na atual sociedade, porém está inserido nesta, principalmente, através das instituições franciscanas (escolas, hospitais, universidades, pousadas, entre outras), evidenciando o vínculo que esse símbolo possui com quem segue essa filosofia de vida. É um sinal de espiritualidade e serve de referência de vida para aquele que o usa, uma tensão de permanente conversão e mudança de vida, em vontade firme de se tornar nova criatura. Deve ser o sinal de que aquele que o ostenta é uma pessoa que busca a sua salvação e de todos os homens na cruz de Jesus Cristo; deve ser um sinal de que aquele que o traz é uma pessoa que vive a esforçar-se por ser pobre, por se despojar e desprender dos bens terrenos para se enriquecer dos valores das bem-aventuranças: o Reino de Deus, a paz, a mansidão, a fraternidade universal, a misericórdia e o perdão; o respeito pela criação, a alegria, a partilha de bens, a luta pela justiça e a paixão por Jesus Cristo Ressuscitado.

Outro símbolo franciscano que está difundido na sociedade é o presépio, o qual é montado no período do Advento e do Natal, a fim de representar o nascimento de Jesus. Assim, os presépios são

elaborados nas igrejas, casas e até praças, relembrando o nascimento do menino Jesus. Mas a maioria do povo não sabe que este foi iniciado por São Francisco (Depoimento do Frei C). ${ }^{5}$

4 Depoimento de um frei da Província Sagrado Coração de Jesus, concedido em 15 de dezembro de 2013.

5 Depoimento de um frei da Província Sagrado Coração de Jesus, concedido em 15 de dezembro de 2013. 
Francisco de Assis sempre procurou viver os ensinamentos do Evangelho em todas suas ações, imitando com plenitude, cuidado e exaltação os passos de Jesus Cristo no seguimento de sua maneira de viver. Assim, três anos antes de sua morte, Francisco idealiza representar a Natividade: "em companhia de Frei Leão e com apoio de um leigo, coloca feno sobre uma pedra para servir de berço ao Menino Jesus; ao lado, imagens de Maria e de José e, nas proximidades, um boi e um burro" (CERON, 2013, p. 10).

Dessa forma, o primeiro presépio foi montado em 24 de dezembro de 1223, no povoado de Grécio (Itália), onde a população local e visitantes puderam participar da Celebração de Natal e contemplaram a essência e a simplicidade do nascimento de Jesus.

Francisco de Assis, quando pensou o presépio quis dar a possibilidade dos mais pobres, humildes, agricultores de sua época também participarem desse evento. Hoje o sistema comercial tenta 'vender' outros sentidos dessa simbologia sagrada (Depoimento Frei B). ${ }^{6}$

O principal objetivo de Francisco era explicar o Natal às pessoas comuns, camponeses que não conseguiam entender a história do nascimento de Jesus. As dificuldades e as limitações de entendimento da maioria do povo não conseguiram tirar de Francisco a liberdade de sonhar e de compartilhar seu conhecimento e sua sabedoria, que bem indicam a grandeza de sua personalidade e de sua prática. A atitude de montar um presépio (um cenário pedagógico) manifesta, antes de tudo, amor pela vida.

A partir dessa data, tornou-se costume em várias culturas montar um presépio quando é chegada a época de Natal. Variam em tamanho, alguns em miniatura, outros em tamanho real e tomam lugar por entre as principais Catedrais, Igrejas e Mosteiros da Europa durante a Idade Média, sendo inclusive montados nas casas de reis e nobres também durante o Renascimento. Nos séculos seguintes, na esteira das grandes navegações e da disseminação do cristianismo pelo mundo, a tradição do presépio natalino é introduzida nos diversos povos, nos diferentes continentes. No século XVIII, com o advento da industrialização, o costume de montar o presépio nas casas comuns se disseminou pela Europa e pelo mundo e passou a representar, muito mais, uma prática comercial, desvinculada da espiritualidade que o originou.

6 Depoimento de um frei da Província Sagrado Coração de Jesus, concedido em 15 de dezembro de 2013. 
Sendo assim, observa-se que, na atualidade, o presépio, além de ser um adorno nas igrejas cristãs, praças e residências no período de Natal, é utilizado pelo comércio, ou seja, perde seu significado original que remete à maneira simples do nascimento de Jesus e adquire um significado mercantil, uma vez que é utilizado para induzir ao consumismo.

A saudação franciscana de "Paz e Bem" tem sua origem vinculada ao envio dos discípulos, ou seja, o próprio Cristo pediu aos seus apóstolos que cumprimentassem as pessoas que os acolhiam com a expressão "a paz esteja nesta casa" (Lc 10,5). Certamente, foi o evangelho de Lucas que influenciou Francisco de Assis a redefinir o modo de anunciar o evangelho e incentivou os frades franciscanos a utilizarem essa saudação a todas as pessoas que encontrassem pelo caminho e que acolhessem a palavra de Deus.

No período em que Francisco nasceu, existia na região de Assis um bispo, conhecido como Mestre Rufino, que escreveu um tratado denominado "De Bono Pacis", isto é, "o bem da paz". Este documento influenciou o pensamento místico de Francisco sobre o significado da paz.

O bem a que Francisco se refere é o próprio Deus. Por isso, desejar o bem significa ter em Deus o ponto central da vida (viver em Deus, com Deus e por Deus), experiência vivida por Francisco. Assim, a saudação de paz e bem para os frades Capuchinhos significa

uma forma de saudar alguém que reflete a imagem de Cristo, que veio ao mundo para trazer o bem e a paz, e nós franciscanos queremos transmitir esta mensagem para a sociedade atual (Depoimento Frei G). ${ }^{7}$

Logo, compreende-se que a saudação de $\mathrm{P} a z$ e Bem é mais que um cumprimento formal dos franciscanos, e sim, uma opção por um estilo de vida, um seguimento aos ensinamentos de Jesus.

Uma forma fraterna que todo franciscano utiliza para saudar. Expressão de alegria e de paz interior. Saudar com a paz de Cristo as pessoas com as quais se encontram durante a caminhada de vida. Atualmente é uma expressão muito forte, especialmente, por aqueles que abraçam a proposta franciscana (Depoimento Frei E). ${ }^{8}$

7 Depoimento de um frei da Província Sagrado Coração de Jesus, concedido em 15 de dezembro de 2013.

8 Depoimento de um frei da Província Sagrado Coração de Jesus, concedido em 15 de dezembro de 2013. 
A saudação franciscana de Paz e Bem pode ser considerada um estímulo para que os Capuchinhos persistam na fé e na entrega à vida religiosa, colaborando, assim, para a construção de uma sociedade mais justa e fraterna.

Os votos perpétuos franciscanos representam a aceitação de seguir este modo de vida, ou seja, após as etapas de preparação (aspirantado, pré-postulantado, noviciado e pós-noviciado) é chegado o momento de o jovem frade assumir definitivamente a vida religiosa.

Para seguir uma vida religiosa pautada na fé, na comunhão e no auxílio aos mais necessitados, os frades Capuchinhos realizam votos de pobreza, de castidade e de obediência. Assim,

os votos que os frades assumem é uma proposta evangélica feita por aqueles que desejam viver uma vida de total entrega a Deus. Sem possuir nada de próprio, vivendo de forma comum com os demais irmãos, seguindo as propostas estabelecidas pela Ordem (Depoimento Frei E). ${ }^{9}$

Os votos perpétuos fortalecem a vivência religiosa e constituem a renúncia de valores efêmeros impostos pela atual sociedade, permitindo que os franciscanos renunciem às concepções modernas, como o egocentrismo, a banalização do sexo, o individualismo e o apego aos bens materiais.

Os votos são conhecidos também como conselhos evangélicos. A vida religiosa em si é um chamado para ser um sinal profético no mundo e em seu contexto atual, por isso os votos são este sinal do Reino de Deus entre nós e que terá sua plenitude na eternidade (Depoimento Frei A).

Sendo assim, os três votos professados estão alicerçados pelo Evangelho de Mateus: "Todo aquele que tiver deixado casas, irmãos, irmãs, pai, mãe, filhos, campos, por causa do meu nome, receberá muitas vezes mais, e terá como herança a vida eterna" (Mt 19.29). Com base no Evangelho, os Capuchinhos professam seus votos, afirmando compromissos de vida com a prática da pobreza, da castidade e da obediência.

9 Depoimento de um frei da Província Sagrado Coração de Jesus, concedido em 15 de dezembro de 2013. 
$\mathrm{O}$ voto de pobreza remete ao fato de os franciscanos renunciarem aos bens materiais, contentando-se com o necessário para viver e esquecendo-se do supérfluo. Os Capuchinhos repartem o que têm com os demais membros da fraternidade, constituindo uma maneira simples de viver, sem ostentação e baseada na solidariedade com aqueles que pouco têm.

O voto de obediência é um exercício de aceitação à hierarquia estipulada dentro das fraternidades franciscanas, sendo que os adeptos dessa filosofia de vida devem-se fazer obedientes como Cristo foi "obediente até a morte e morte de cruz" $(F l 2,8)$, abnegando suas próprias vontades de forma humilde. Também, pode ser entendido como obediência ao projeto de Deus, aos ritos e às consagrações.

Por último, o voto de castidade é uma promessa de celibato, que implica viver sem casar e/ou manter relações sexuais com outra pessoa. Entretanto, a ideia principal desse voto é a busca pelo amor de Deus e a dedicação aos serviços pastorais, uma vez que não se constituirá uma família. A partir do voto de castidade, os Capuchinhos vivenciam com maior plenitude as suas experiências religiosas e suas vidas em fraternidade.

Desse modo, os votos perpétuos podem ser entendidos como um compromisso assumido entre o jovem frade com a Igreja e a Ordem à qual pertence, nesse caso, a Ordem dos Frades Menores Capuchinhos. Além disso, é uma opção de vida e uma escolha questionada pela atual sociedade, visto que se constroem valores diferentes daqueles que predominam. Os votos são orientações para um modelo de vida simples, fiel e humilde.

\section{Conclusão}

A presença e a ação religiosa da Ordem dos Frades Menores Capuchinhos tiveram reflexos em três períodos na história da territorialidade do Rio Grande do Sul e do Brasil. Primeiro, o da vinda dos freis Capuchinhos para o território gaúcho (1896), com o surgimento da primeira Província (a Província Sagrado Coração de Jesus) em território brasileiro, sob custódia da Província de Saboia (França), que contribuiu, não só para o atendimento espiritual dos imigrantes italianos em território gaúcho, mas também possibilitou melhorias na vida destes, através de diferentes assistências educacionais e outros trabalhos sociais. Segundo, a elevação da Província Sagrado Coração de Jesus à condição 
de Comissariado Provincial (1924), já com quatro conventos (Garibaldi, Flores da Cunha, Veranópolis e Porto Alegre), duas residências (Vacaria e Sananduva), cinco paróquias (Flores da Cunha, Veranópolis, Vacaria, Sananduva e Paternon-Porto Alegre) e um jornal. A emancipação da Província Sagrado Coração de Jesus ocorreu em 24 de julho de 1942. Os Freis Capuchinhos marcam presença em diferentes frentes de atuação e apostolado no território gaúcho. Terceiro, a espacialização territorial e a difusão para as regiões Centro-Oeste e Norte do Brasil e para dois países da América Central, Haiti e República Dominicana, e a emancipação da Província Nossa Senhora de Fátima - Brasil Central (em 1982).

Em relação à simbologia franciscana, considerada uma utopia, continua sendo atual, porque as marcas de sua espiritualidade, profundamente fraterna, ainda respondem às aspirações do mundo atual. Os bens simbólicos aqui analisados estão relacionados à utopia franciscana e, tantas vezes, usados e 'consumidos' mas não vivenciados em sua essência primeira e profunda.

Constatou-se que o simbolismo franciscano está presente na atual sociedade, mesmo que esta não perceba, principalmente, difundido através do presépio e do Tau. Também os votos e a saudação de "Paz e Bem" apresentam maiores significados para aqueles que praticam essa filosofia de vida.

\section{Referências}

BÍBLIA. Bíblia Sagrada. 9. ed. São Paulo: Ave Maria, 1966.

BÍBLIA. 2000. Bíblia Sagrada: Edição Pastoral. Traduzida em português por Ivo Storniolo; Euclides Martins Balancin; José Luiz Gonzaga do Prado. 40a impressão. São Paulo: Paulus, 2000.

BRUM NETO, Helena. Região cultural: a construção de identidades culturais no Rio Grande do Sul e sua manifestação na paisagem gaúcha, 2007, 319 p. Dissertação de Mestrado (Mestrado em Geografia) - Universidade Federal de Santa Maria, Santa Maria, 2007.

CERON, Ida Tereza. A mística dos presépios: história e herança franciscana. $O$ Santuário, Santa Maria, RS, ano XXXVI, p. 10, dez. 2013.

CLAVAL, Paul. A geografia cultural. Tradução: Luiz Fugazzola Pimenta; Margareth Afeche Pimenta. Florianópolis: Ed. da UFSC, 1999.

CONTI, Martino. Estudos e pesquisas sobre o franciscanismo das origens. Petrópolis, RJ: Vozes, 2004. 
CORRÊA, Roberto Lobato; ROSENDAHL, Zeny (Orgs.). O papel da nova geografia cultural na compreensão da ação humana. In: Matrizes da Geografia Cultural. Rio de Janeiro: EdUERJ, 2001.

CORREAA, Roberto Lobato; ROSENDAHL, Zeny (Orgs.). Introdução à geografia cultural. Rio de Janeiro: Bertrand Brasil, 2003.

FAUSTO, Bóris. História do Brasil. São Paulo: EDUSP, 2000.

GIRON, Loraine Slomp; HERÉDIA, V. Cultura e religião. História da Imigração Italiana no Rio Grande do Sul. Porto Alegre: Est, 2007.

MERINO, José. Antonio. Humanismo Franciscano: Franciscanismo e mundo atual. Petrópolis: FFB.1999.

MERLO. Grado Giovanni. Em nome de São Francisco: história dos frades menores e do franciscanismo até início do século XVI. Petrópolis, RJ: Vozes, 2005.

MOREIRA, Alberto da Silva. Inspiração Franciscana para a Educação. In: Revista Vidya, edição especial, jul. 2001. ISSN 0104-270X.

VISALLI, Angelita Marques. O Crucifixo de São Damião: assim Cristo se manifesta a Francisco de Assis. Notandum, São Paulo, ano XVI, v. 32, p. 85-100, maio-ago. 2013. Disponível em: <http://www.hottopos.com/notand32/>. Acessado em: 02 jan. 2014.

VORREUX, Damião. Um símbolo franciscano, o Tau: história, teologia e iconografia. Braga: Editorial Franciscana, [s/d.].

ZAGONEL, Carlos Albino. Igreja e imigração: capuchinhos de Saboia e seu contributo à igreja do Rio Grande do Sul. Porto Alegre: Escola Superior de Teologia São Lourenço de Brindes, Sulina, 1975.

ZAGONEL, Carlos Albino. Capuchinhos de Saboia no Rio Grande do Sul. In: COSTA, Rovílio; BONI, Luis A. Os capuchinhos do Rio Grande do Sul. Porto Alegre: Edições EST (Escola Supeior de Teologia e Espiritualidade Franciscana), 1996. p. 15-21.

ZAGONEL, Carlos Albino. Província do Rio Grande do Sul: Sagrado Coração de Jesus. In: ZAGONEL, Carlos Albino (Org.). Capuchinhos no Brasil. Porto Alegre: Conferência dos Capuchinhos do Brasil, 2001. 